\title{
Analisis Efektifitas Metode Weighted Product dan TOPSIS dalam Mendiagnosa Serangan Asma
}

\author{
(Effectiveness Analysis of Weighted Product and TOPSIS Methods in Diagnosing \\ Asthma Attacks)
}

\author{
Ade Ragil Purwandani ${ }^{*}$, Ario Yudo Husodo, Fitri Bimantoro \\ Program Studi Teknik Informatika, Fakultas Teknik, Universitas Mataram \\ J1. Majapahit 62, Mataram, Lombok NTB, INDONESIA \\ Email:aderaaagilp@gmail.com, [ario, bimo]@unram.ac.id
}

*Penulis korespondensi

\begin{abstract}
Asthma attack was one of the disease having symptoms of nearly the same each other. So that it can be grouped into some of symptoms by sub this shows a tendency to each. This is in accordance with the application of a method of WP and TOPSIS that is used in diagnose an asthma attack. Not widely used method of WP or TOPSIS in diagnose asthma attack because Commonly used in the support system decision so as to give diagnose that is less valid. In this research, the WPTOPSIS method was combined by utilizing the advantages of each method in providing output and fix by computation from a method of WP-TOPSIS with a disregard a couple of things as the value of the cost of which is not possessed expert system. So it expected to results from output better. By using 40 data of experiment to the 2 people experts obtained the results of the level of accuracy of the average namely WP 21,25\%, TOPSIS $21,25 \%$ and combined WP-TOPSIS $65 \%$. Obtained increase in extent accuracy namely 43,75\%, Thus methods combined better than WP and TOPSIS in its use in expert system diagnose asthma attack.
\end{abstract}

Key words: Weighted Product, TOPSIS, Asthma Attack

\section{PENDAhUluan}

Sistem pakar adalah suatu sistem yang terkomputerisasi dan dapat menirukan seorang pakar dalam mengatasi masalah sesuai dengan pengetahuan yang dimilikinya. Penyelesaian masalah dapat diuji dan hasil pengujian dibandingkan dengan hasil yang diberikan oleh seorang pakar [1]. Di bidang kedokteran, sistem pakar menyangkut diagnosis suatu penyakit berdasarkan gejala yang dialami. Salah satu penyakit yang akan dikaji ialah mengenai diagnosis serangan asma. Serangan asma adalah suatu kelainan berupa peradangan pada saluras pernafasan yang dapat menyebabkan bronkus hipereaktivitas terhadap rangsangan, ditandai dengan gejala episodik berulang seperti mengi, batuk, sesak nafas dan rasa berat di dada terutama pada malam hari atau dini hari. Serangan asma bersifat fluktuatif atau hilang timbul yang artinya dapat tenang tanpa gejala dan tidak mengganggu aktifitas tetapi dapat dengan gejala ringan hingga berat bahkan dapat mengancam kehidupan[2]. Dalam penelitian ini serangan asma terpilih sebagai penyakit yang akan didiagnosa dikarenakan serangan asma memiliki gejala yang hampir sama satu sama lainnya. Sehingga kesamaan gejala tersebut dapat dikelompokkan menjadi beberapa sub gejala dan diberikan pembobotan yang berbeda sesuai dengan tingkat kepentingannya suatu sub gejala. Tidak semua penyakit dapat dikelompokkan menjadi suatu gejala dan sub gejala.

Pada penelitian ini dilakukan pengolahan data dengan menggunakan Fuzzy Multiple Attribute Decision Making (FMADM). FMADM merupakan suatu metode yang digunakan untuk mencari alternatif terbaik dari sejumlah alternatif dengan kriteria tertentu. Untuk menyelesaikan masalah FMADM digunakan metode Weighted Product (WP) dan Technique for Order of Preference by Similarity to Ideal Solution (TOPSIS). Dalam perhitungannya, metode Weighted Product menggunakan perkalian untuk dapat menghubungkan rating antar atributnya, dimana dari setiap rating atribut dipangkatkan lebih dulu dengan bobot yang bersangkutan. Metode TOPSIS dipilih sebagai metode pemilihan alternatif terbaik dikarenakan menggunakan prinsip bahwa alternatif terbaik yang terpilih diharuskan memiliki jarak terdekat dengan solusi ideal positif dan terjauh dari solusi ideal negatif.

Masing-masing metode WP dan TOPSIS memiliki kekurangan dan kelebihan. Kekurangan metode WP antara lain dikarenakan dalam penggunaannya metode ini di sistem pakar menyebabkan tidak memiliki cost dan benefit untuk kriterianya sehingga mempengaruhi salah satu perhitungan untuk menentukan perangkingan sehingga dengan kelebihan metode TOPSIS yang lebih baik dalam hal perangkingan dikarenakan dalam penentuan preferensi alternatifnya berdasarkan solusi ideal positif dan solusi ideal negatif. Selain itu kelebihan metode WP antara lain pada saat pembobotan awal dilakukan perbaikan bobot sehingga dapat menutupi kekurangan metode TOPSIS yaitu tidak memiliki perhitungan untuk pembobotan. Sehingga dengan memanfaatkan kelebihan dan kekurangan masing-masing metode, dilakukan penelitian ini dengan menggabungkan masing-masing perhitungan metode tersebut.

Adapun tujuan dari dilakukannya penelitian ini yaitu untuk mengetahui bagaimana cara menerapkan penggabungan dari metode Weigthed Product dan TOPSIS dalam mendiagnosa serangan asma serta dapat mengetahui efektifitas dari penggabungan kedua metode dibandingkan 
dengan metode WP dan metode TOPSIS dengan cara mengetahui peningkatan persentase tingkat akurasi.

\section{Penelitian Terkait}

Sistem pakar mengenai penyakit asma telah dilakukan dalam beberapa penelitian, penelitian tersebut menggunakan metode-metode antara lain Certainty Factor, Fuzzy Tsukamoto, Expert System Development Life Cycle (ESDLC) dan juga Fuzzy Inference System[3][4][5][6]. Dari keempat penelitian yang membahas mengenai sistem pakar didapatkan beberapa kesimpulan. Serangan asma merupakan suatu penyakit lima besar penyebab kematian di Dunia sehingga serangan asma merupakan penyakit yang perlu dideteksi sejak dini berdasarkan gejala yang dialami. Untuk tingkat akurasi atau validitas dari penelitian yang membahas serangan asma, masih terdapat yang tidak diketahui tingkat validitasnya dikarenakan tidak menggunakan pengetahuan dari pakar spesialis untuk serangan asma yaitu dokter spesialis paru. Tetapi ada pula yang memiliki tingkat akurasi atau validitas yaitu sekitar $72 \%$ dan $90 \%$. Akurasi yang didapatkan tersebut hanya menggunakan 20 data uji sehingga masih diperlukan penambahan data uji agar lebih akurat. Serangan asma yang didiagnosa pun hanya 3 level yaitu ringan, sedang berat sedangkan terdapat 1 level lagi yang dapat didiagnosa yaitu ancaman jiwa. Sehingga keterbaruan dari penelitian ini sendiri untuk penyakit serangan asma yaitu menggunakan pengetahuan 2 orang pakar yang akan dilibatkan dalam akuisisi pengetahuan sampai pengujian, memiliki tingkat akurasi yang cukup baik atau terdapat peningkatan, menggunakan 40 data uji yang didiskusikan dengan 2 orang pakar serta mendiagnosa 4 alternatif penyakit yaitu serangan asma ringan, sedang, berat dan ancaman jiwa.

Metode WP yang biasa digunakan dalam sistem pendukung keputusan beberapa kali juga digunakan mendiagnosa suatu penyakit dalam sistem pakar. Beberapa penelitian yang menggunakan metode WP dalam mendiagnosa penyakit yaitu pada penyakit paru-paru dan penyakit hepatitis[7][8]. Metode WP pun dapat digabungkan dengan metode lainnya, salah satu penelitian melakukan penggabungan metode WP dengan Certainty Factor pada penyakit malaria[9]. Adapun kesimpulan dari beberapa metode tersebut ialah metode WP digunakan untuk mendiagnosa penyakit dan kemudian memberikan keputusan berupa tiga zona kesehatan dan tidak melakukan pengujian sistem dengan diagnosa pakar. Penggunakan metode WP dapat dilakukan dengan cara menambahkan alternative Pasien yang berguna untuk membandingkan hasil alternative pasien dengan alternative penyakit agar terpilih penyakit yang diderita. Sedangkan untuk penggabungan metode WP dengan metode lainnya didapatkan akurasi $84 \%$ hanya dengan 5 skenario pengujian. Sehingga didapatkan kekurangan yaitu metode WP belum cukup baik digunakan untuk mendiagnosa suatu penyakit karena perhitungan yang dimiliki untuk SPK serta memerlukan lebih banyak data uji agar lebih diketahui tingkat keakuratan sistem. Sehingga keterbaruan penelitian ini dibandingkan dengan yang sebelumnya yaitu menggunakan alternative Pasien untuk melihat perbandingan antara Pasien dengan alternative penyakit, menggunakan 40 data uji serta memperhatikan perhitungan WP dengan menghilangkan perhitungan yang berkaitan dengan nilai cost atau biaya yang tidak dimiliki oleh diagnosa serangan asma.

Metode TOPSIS yang biasa digunakan dalam sistem pendukung keputusan beberapa kali juga digunakan mendiagnosa suatu penyakit dalam sistem pakar. Beberapa penelitian yang menggunakan metode TOPSIS dalam mendiagnosa penyakit yaitu pada penyakit dan hama tanaman salak[10]. Metode TOPSIS pun dapat digabungkan dengan metode lainnya, salah satu penelitian melakukan penggabungan metode TOPSIS dengan Simple Additive Weighting (SAW) pada penyakit anak[11]. Dari penelitian tersebut didapatkan beberapa kesimpulan yaitu, metode TOPSIS tidak digunakan untuk mendiagnosa penyakit melainkan hanya menentukan rangking tertinggi dan tidak melakukan pencocokan dengan hasil diagnosa pakar. Serta dengan menggabungkan metode TOPSIS dengan metode lainnya didapatkan tingkat akurasi 76\% hanya dengan 10 data uji dari responden yang menyatakan keluarannya sama dengan diagnosa Pakar. Tetapi kekurangan dari metode ini pun yaitu tidak menetapkan cara menentukan pembobotan sehingga menyebabkan akurasi dapat berbeda-beda. Sehingga keterbaruan dari penelitian inipun yaitu menggunakan pembobotan dari metode WP serta menggabungkannya dengan metode WP agar didapatkan tingkat akurasi yang lebih baik.

Terdapat beberapa penelitian yang melakukan perbandingan antara metode WP dan TOPSIS antara lain pada kasus penentuan bantuan kemiskinan dan perekrutan siswa/mahasiswa PKL[12][13]. Dari penelitian tersebut didapatkan beberapa kesimpulan bahwa metode WP dan TOPSIS dapat memberikan keluaran yang sama untuk peringkat 3 besar alternative. Didapatkan pula hasil bahwa metode WP dan TOPSIS memiliki keunggulan masingmasing, untuk WP unggul dalam stabilitas data 100\% dibandingkan dengan TOPSIS 80\% sedangkan TOPSIS unggul dalam tingkat akurasi tinggi dengan persentase error rate rendah yaitu $27 \%$ dibandingkan dengan WP $33 \%$. Sehingga dengan keunggulan dari kedua metode tersebut, penelitian ini memiliki keterbaruan yaitu penggabungan metode WP dan TOPSIS yang belum banyak digunakan dalam sistem pakar serta melibatkan Pakar spesialis diagnosa serangan asma yang diharapkan memiliki hasil berguna dengan tingkat akurasi atau validitas yang cukup baik dibandingkan dengan penelitian- 
penelitian sebelumnya dengan menggunakan 40 data uji dan 4 alternatif penyakit yang akan didiagnosa.

Berdasarkan dari beberapa penelitian yang menjadi tinjauan pustaka tersebut, penulis hendak melakukan suatu penelitian yaitu "Analisis Efektifitas Metode WP dan TOPSIS dalam Mendiagnosa Serangan Asma". Penelitian ini memilih serangan asma sebagai penyakit yang akan didiagnosa dikarenakan gejala yang dimiliki satu penyakit dengan yang lainnya sama sehingga memudahkan untuk dilakukan pengelompokan gejala sesuai dengan cara yang dilakukan metode WP dan TOPSIS. Penelitian ini memilih metode WP dan TOPSIS dikarenakan seperti yang dijelaskan pada penelitian terkait mengenai perbandingan metode WP dan TOPSIS, kedua metode ini miliki kriteria yang sama berdasarkan beberapa pengujian metode dan keduanya tidak banyak digunakan dalam suatu sistem pakar.

\section{Metode Penelitian}

\section{A. Analisis Kebutuhan Sistem}

Pada tahap ini dilakukan beberapa hal antara lain studi literatur dan pengumpulan data. Studi literatur yang dilakukan yaitu dengan cara mengumpulkan data dari berbagai skripsi, jurnal dan buku yang berkaitan dengan penelitian ini. Tujuan dilakukannya studi literatur agar dapat mengetahui kekurangan dan kelebihan dari berbagai penelitian sebelumnya sehingga dapat digunakan sebagai acuan dalam mengembangkan sistem. Pengumpulan data dilakukan dengan melakukan wawancara kepada pihak yang bersangkutan. Untuk penelitian ini dilakukan wawancara dengan dua orang pakar Dokter Spesialis Paru yaitu dr. Salim S. Thalib Sp.P yang bertugas di RSUD Provinsi NTB dan dr Risky Irawan, Sp.P, MARS yang bertugas di Rumah Sakit Risa Sentra Medika. Wawancara dilakukan dengan tujuan untuk mengetahui serangan asma berdasarkan ringan atau beratnya gejala serta mengetahui pengelompokan gejala berdasarkan kriterianya. Serta pakar juga terlibat dalam pengujian sistem dimana melakukan diagnosa terhadap gejala yang dialami pasien dan disesuaikan dengan hasil diagnosa sistem.

\section{B. Akuisisi Pengetahuan}

Akuisisi pengetahuan adalah pengumpulan data dari pakar ke dalam sistem berupa penyakit, gejala dan pembobotan. Pakar untuk melakukan konsultasi mengenai serangan asma yaitu Dr. Salim S. Thalib Sp.P merupakan seorang spesialis paru yang aktif bekerja di RSUD Provinsi NTB. Bobot yang diberikan oleh Pakar berdasarkan tingkat kepentingan suatu gejala dengan gejala yang lainnya. Pengelompokan gejala beserta bobotnya seperti pada Tabel I dan akuisisi pengetahuan pada Tabel II.

\section{Mesin Inferensi}

Mesin inferensi berperan untuk mengelola data masukan sehingga mendapatkan hasil diagnosa. Gambar 1 merupakan flowchart dari mesin inferensi sistem pakar berbasis website yang menerapkan hasil analisis metode
WP dan TOPSIS dalam mendiagnosa serangan asma. Dalam penelitian ini proses perhitungannya dengan menggabungkan metode WP dan TOPSIS sehingga memerlukan nilai bobot yang sudah tersimpan dalam basis pengetahuan.

TABEL I. Pengelompokan gejala beserta nilai bobot

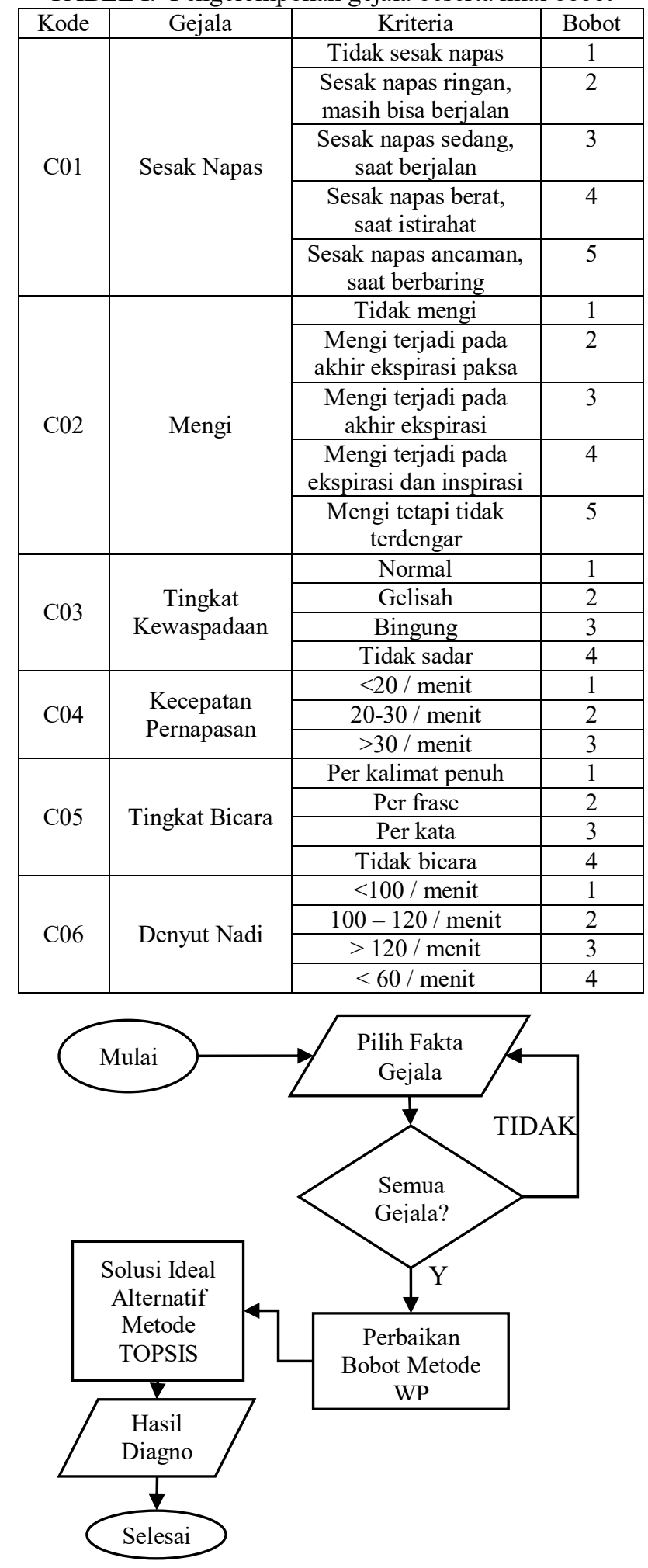

Gambar 1. Flowchart Sistem Pakar Diagnosa Serangan Asma. 
TABEL II. Bobot kriteria penyakit

\begin{tabular}{|c|c|c|c|}
\hline Kode & $\begin{array}{c}\text { Nama } \\
\text { Penyakit }\end{array}$ & Gejala & Bobot \\
\hline \multirow{6}{*}{ A01 } & \multirow{6}{*}{$\begin{array}{c}\text { Serangan } \\
\text { Asma } \\
\text { Ringan }\end{array}$} & $\begin{array}{l}\text { Sesak napas tetapi masih } \\
\text { bisa berjalan }\end{array}$ & 2 \\
\hline & & $\begin{array}{l}\text { Mengi terjadi pada akhir } \\
\text { ekspirasi paksa }\end{array}$ & 2 \\
\hline & & $\begin{array}{l}\text { Tingkat kewaspadaan } \\
\text { normal }\end{array}$ & 1 \\
\hline & & $\begin{array}{l}\text { Kecepatan pernapasan } \\
<20 / \text { menit }\end{array}$ & 1 \\
\hline & & $\begin{array}{l}\text { Tingkat bicara per kalimat } \\
\text { penuh }\end{array}$ & 1 \\
\hline & & Denyut nadi $<100 /$ menit & 1 \\
\hline \multirow{6}{*}{ A02 } & \multirow{6}{*}{$\begin{array}{c}\text { Serangan } \\
\text { Asma } \\
\text { Sedang }\end{array}$} & Sesak napas saat berjalan & 3 \\
\hline & & $\begin{array}{l}\text { Mengi terjadi pada akhir } \\
\text { ekspirasi }\end{array}$ & 3 \\
\hline & & $\begin{array}{l}\text { Tingkat kewaspadaan } \\
\text { tampak gelisah }\end{array}$ & 2 \\
\hline & & $\begin{array}{l}\text { Kecepatan pernapasan 20- } \\
30 \text { / menit }\end{array}$ & 2 \\
\hline & & Tingkat bicara per frase & 2 \\
\hline & & $\begin{array}{l}\begin{array}{l}\text { Denyut nadi } 100-120 / \\
\text { menit }\end{array} \\
\end{array}$ & 2 \\
\hline \multirow{6}{*}{ A03 } & \multirow{6}{*}{$\begin{array}{l}\text { Serangan } \\
\text { Asma Berat }\end{array}$} & $\begin{array}{ll}\text { Sesak napas saat } \\
\text { beristirahat }\end{array}$ & 4 \\
\hline & & $\begin{array}{l}\text { Mengi terjadi pada } \\
\text { inspirasi dan ekspirasi }\end{array}$ & 4 \\
\hline & & $\begin{array}{l}\text { Tingkat kewaspadaan } \\
\text { tampak bingung }\end{array}$ & 3 \\
\hline & & $\begin{array}{l}\text { Kecepatan } \\
\text { pernapasan }>30 / \text { menit }\end{array}$ & 3 \\
\hline & & Tingkat bicara per kata & 3 \\
\hline & & Denyut nadi $>120 /$ menit & 3 \\
\hline \multirow{6}{*}{ A04 } & \multirow{6}{*}{$\begin{array}{l}\text { Serangan } \\
\text { Asma } \\
\text { Ancaman } \\
\text { Jiwa }\end{array}$} & $\begin{array}{lll}\begin{array}{l}\text { Sesak napas saat } \\
\text { berbaring }\end{array} & & \\
\end{array}$ & 5 \\
\hline & & $\begin{array}{l}\text { Mengi terjadi tetapi tidak } \\
\text { terdengar }\end{array}$ & 5 \\
\hline & & $\begin{array}{ll}\text { Tingkat } & \text { kewaspadaan } \\
\text { tidak sadar } & \end{array}$ & 4 \\
\hline & & $\begin{array}{l}\text { Kecepatan } \\
\text { pernapasan }>30 / \text { menit }\end{array}$ & 3 \\
\hline & & $\begin{array}{l}\text { Tingkat bicara dengan } \\
\text { tidak bicara }\end{array}$ & 4 \\
\hline & & Denyut nadi $<60 /$ menit & 4 \\
\hline
\end{tabular}

\section{Metode yang diusulkan}

Pada penelitian ini dilakukan sebuah analisis untuk menggabungkan dua buah metode yaitu metode Weighted Product dengan metode TOPSIS. Berikut flowchart metode Weighted Product dan metode TOPSIS pada Gambar 2 dan Gambar 3.

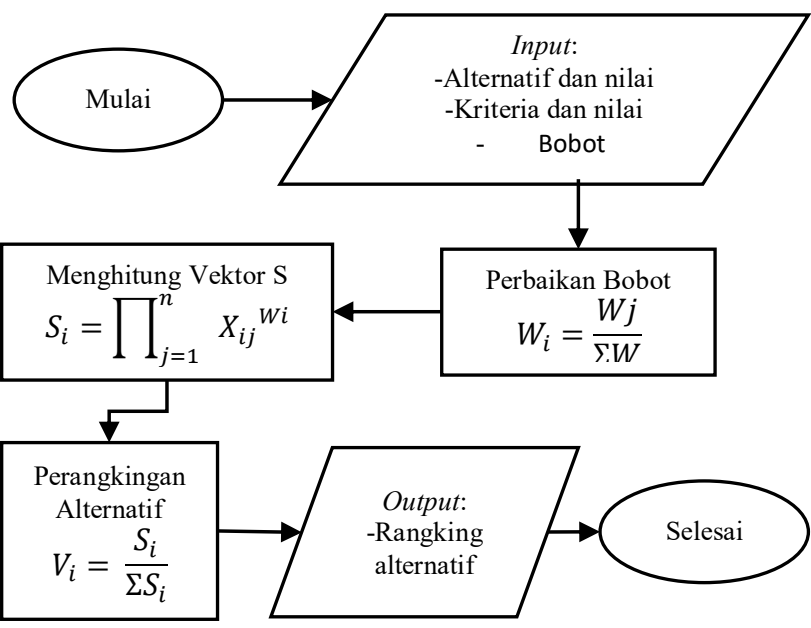

Gambar 2. Flowchart Metode Weighted Product[14].

Terdapat beberapa langkah yang perlu dilakukan untuk perhitungan metode Weighted Product antara lain melakukan perbaikan bobot untuk masing-masing gejala, kemudian menghitung vektor untuk masing-masing penyakit dan terakhir menentukan perangkingan alternatif.

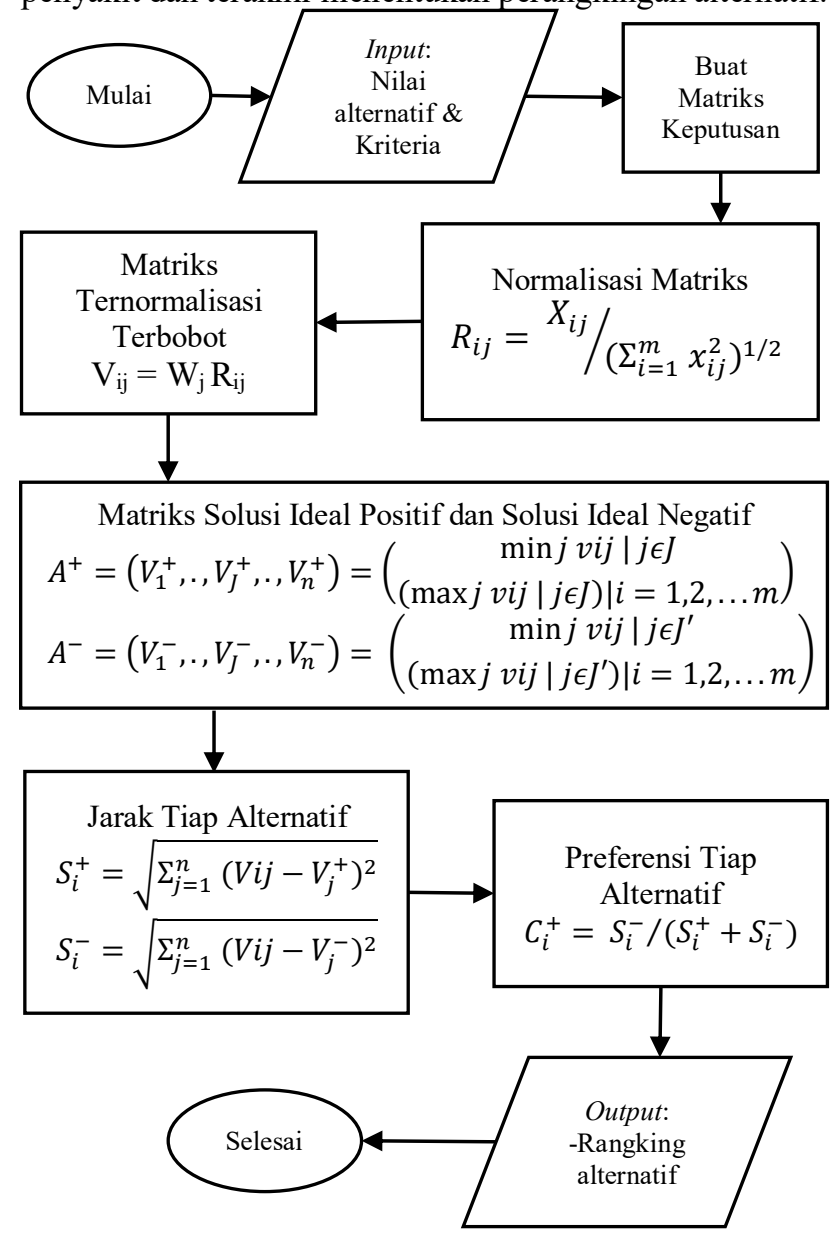

Gambar 3. Flowchart Metode TOPSIS[15].

Langkah metode TOPSIS antara lain melakukan normalisasi terhadap matriks keputusan dan kemudian 
dilakukan normalisasi terbobot. Setelah itu dilakukan perhitungan untuk solusi ideal positif dan solusi ideal negatif. Setelah didapatkan nilai solusi ideal positif dan negatif, dilakukan perhitungan untuk mengetahui jarak tiap alternatif hingga didapatkan preferensi tiap alternatif dan mengurutkan atau merangkingkan alternatif yang terpilih.

Alur proses perhitungan hasil dari penggabungan kedua metode tersebut, sebelum melakukan proses perhitungan sudah disiapkan masukan berupa alternatif dan nilai alternatif, kriteria dan nilai kriteria serta nilai bobot masukan. Selanjutnya, untuk penelitian ini terdapat pengabungan yang dilakukan yaitu, pertama dilakukan perbaikan bobot dengan metode WP, kedua dilakukan pembuatan matriks normalisasi hasil dari memangkatkan matriks keputusan dengan nilai perbaikan bobot untuk masing-masing kriteria, ketiga dilakukan matriks ternormalisasi terbobot pada metode TOPSIS atau perkalian antara hasil langkah kedua dengan bobot masukan pasien dan kemudian dicari nilai maksimum dan minimum dari masingmasing kriteria, keempat dilakukan proses perhitungan solusi ideal positif dan solusi ideal negatif sesuai dengan cara pada metode TOPSIS, kelima dilakukan proses metode TOPSIS yaitu perhitungan jarak alternative dan keenam dilakukan proses metode TOPSIS yaitu perhitungan preferensi alternatif yang terpilih. Pada penelitian ini dilakukan pula penambahan alternatif pasien pada seluruh perhitungan. Hal tersebut dilakukan karena berguna untuk melakukan persamaan antara hasil perhitungan alternatif pasien dengan alternatif penyakit yang nantinya akan terpilih. Dilakukan perhitungan untuk menentukan selisih antara alternatif pasien dengan seluruh alternatif penyakit dimana dengan selisih terkecil akan dipilih sebagai alternatif terbaik. Gambar 4 merupakan flowchart metode Gabungan.

Masing-masing metode WP dan TOPSIS memiliki kekurangan dan kelebihannya masing-masing. Untuk metode Weighted Product memiliki kekurangan antara lain tidak banyak digunakan dalam pengambilan keputusan terutama pada sistem pakar dikarenakan dalam sistem pakar tidak memiliki cost sehingga pada saat perhitungan menyebabkan kesalahan berupa alternatif yang terpilih adalah alternatif dengan nilai bobot kriteria yang tertinggi. Sedangkan untuk metode TOPSIS memiliki kekurangan antara lain metode ini kurang baik dalam mendapatkan bobot dikarenakan tidak memperhitungkan hubungan antara kriteria. Tetapi, dalam setiap kekurangan metode tersebut terdapat kelebihan yang dimiliki masing-masing metode. Untuk metode Weighted Product memiliki kelebihan antara lain konsep yang sederhana untuk menentukan pembobotan terhadap kriteria yang memiliki nilai hampir sama. Sedangkan kelebihan metode TOPSIS antara lain mempertimbangkan perhitungan jarak antara solusi ideal positif dan negatif. Dengan kelebihan dan kekurangan masing-masing metode, dipenelitian kali ini dilakukan sebuah analisis dengan menggabungkan kedua metode tersebut dengan tujuan untuk mengetahui tingkat efektifitas dari penggabungan metode ini.

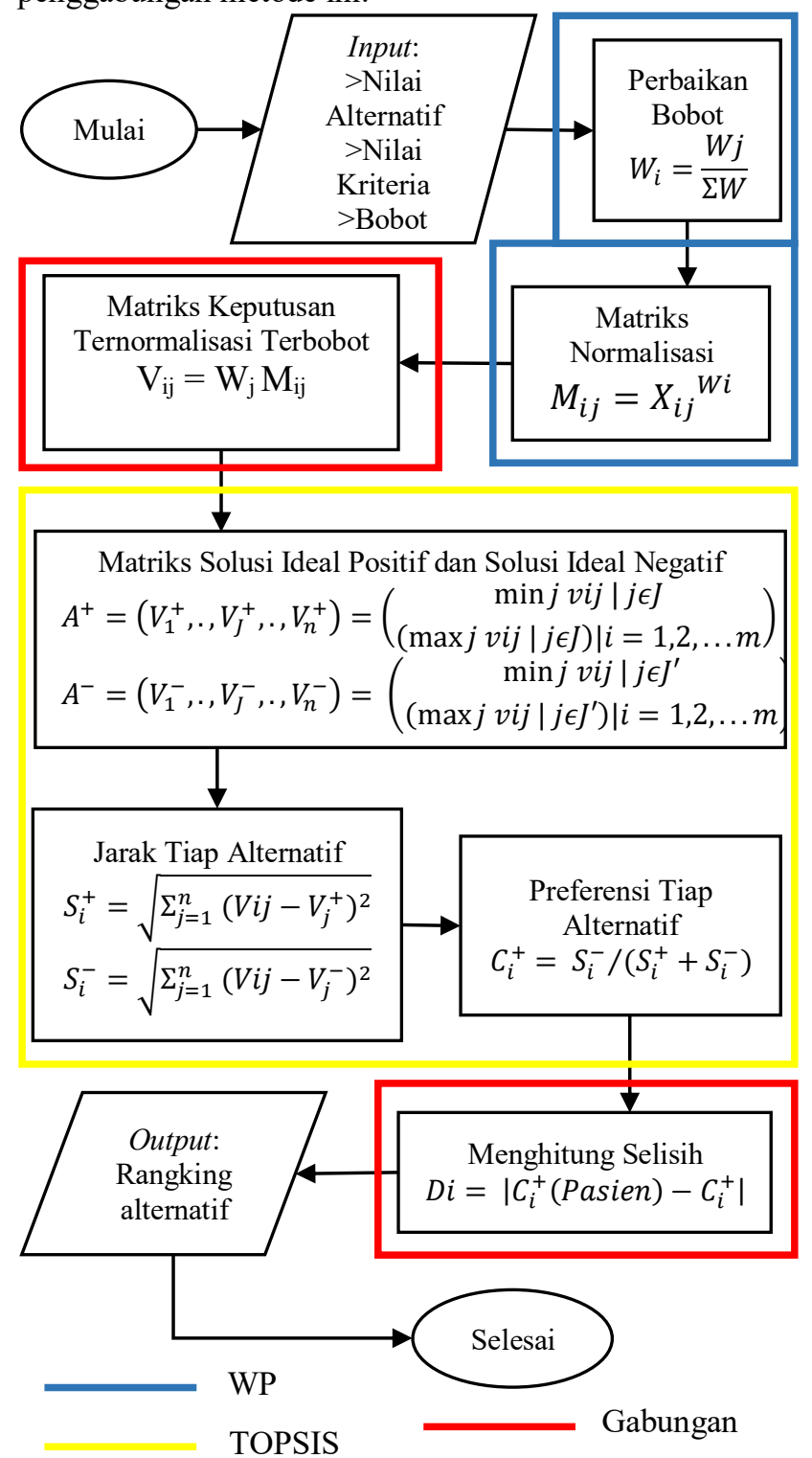

Gambar 4. Flowchart Metode Gabungan..

\section{HASIL DAN PEMBAHASAN}

\section{A. Hasil Implementasi}

Pada implementasi sistem pakar akan dibahas alur kerja sistem beserta interface dari sistem pakar diagnosa serangan asma. Sistem pakar diagnosa serangan asma merupakan bentuk implementasi dari pengujian analisis metode Weighted Product, TOPSIS dan Gabungan dari kedua metode. Pada implementasi sistem pakar meliputi bagian diagnosa beserta hasil perhitungan dan kesimpulan serangan asma yang diderita. Untuk pilihan halaman diagnosa terdapat pada Gambar 5 dan halaman memilih gejala untuk seluruh metode terdapat pada Gambar 6. 


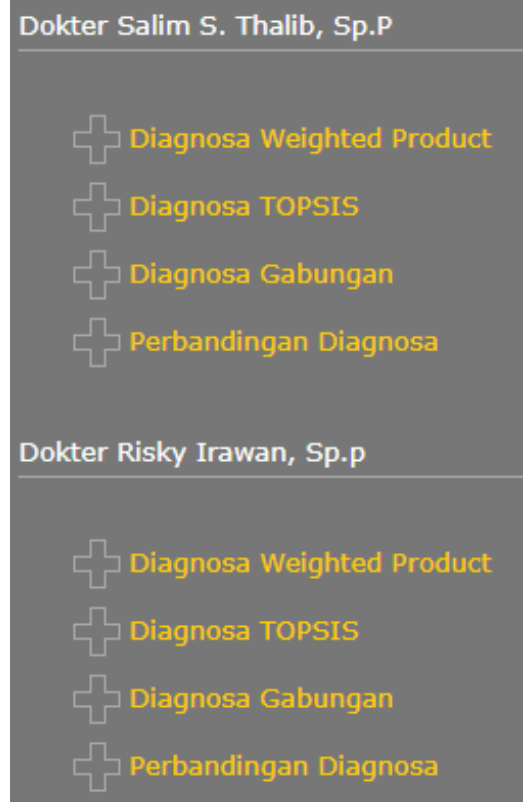

Gambar 5. Halaman Diagnosa Dokter

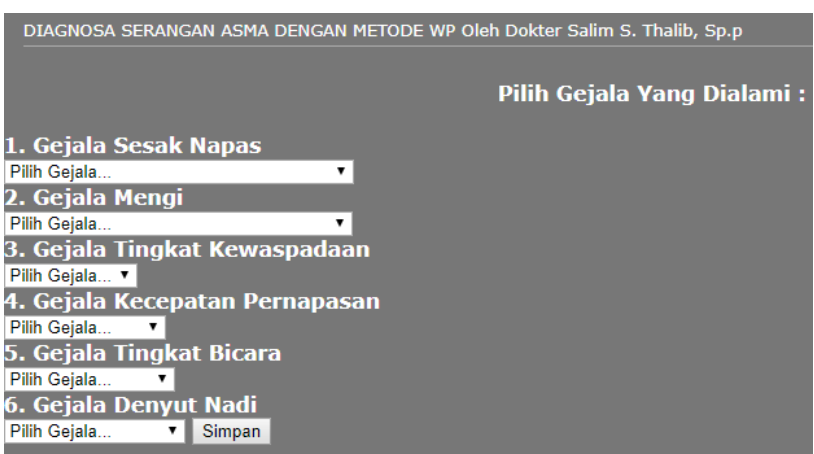

Gambar 6. Halaman Memilih Gejala

Pada Gambar 7 dan Gambar 8 merupakan tampilan dari halaman diagnosa dan hasil diagnosa metode WP oleh Dokter Salim Sp.P. Halaman ini menampilkan gejala serangan asma dan pengguna memasukkan subgejala dari masing-masing gejala kemudian menekan 'Simpan' dan akan ditampilkan halaman hasil diagnosa sesuai. Hal yang ditampilkan antara lain perhitungan untuk metode Weighted Product beserta kesimpulan serangan asma yang diderita. Tampilan halaman diagnosa dan hasil diagnosa ini sama untuk metode TOPSIS dan metode Gabungan serta sama untuk pakar lainnya yaitu Dokter Risky Sp.P.

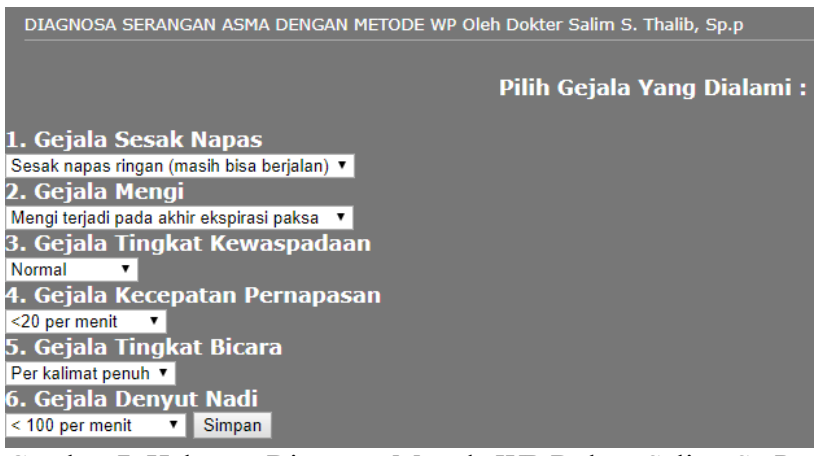

Gambar 7. Halaman Diagnosa Metode WP Dokter Salim Sp.P

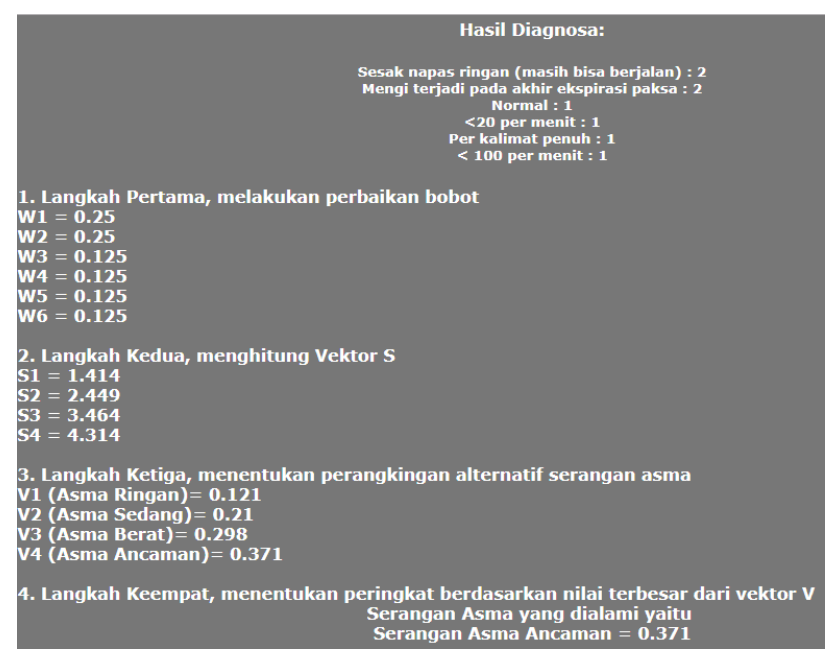

Gambar 8. Halaman Hasil Diagnosa Metode WP

\section{B. Pengujian Teoritis}

Pengujian perhitungan teoritis dilakukan untuk mengetahui keluaran dari perhitungan sistem sesuai dengan keluaran dari perhitungan teoritis. Pengujian perhitungan teoritis dilakukan pada salah satu contoh kasus seperti pada Tabel III. Berikut merupakan perhitungan dari metode Gabungan yang digunakan dalam penelitian ini.

TABEL III. Contoh Kasus Dokter Salim Sp.P

\begin{tabular}{|c|l|c|}
\hline Nama Kriteria & \multicolumn{1}{|c|}{ Sub-kriteria } & Skor \\
\hline Sesak Napas & Saat berjalan merasa sesak & 2 \\
\hline Mengi & $\begin{array}{l}\text { Mengi terjadi pada inspirasi \& } \\
\text { ekspirasi }\end{array}$ & 2 \\
\hline Unik & Tingkat kewaspadaan gelisah & 2 \\
\hline $\begin{array}{c}\text { Kecepatan } \\
\text { Pernapasan }\end{array}$ & $20-30 /$ menit & 1 \\
\hline Tingkat Bicara & Per frase & 1 \\
\hline Denyut Nadi & $100-120$ menit & 1 \\
\hline
\end{tabular}

\section{Langkah pertama, melakukan perbaikan bobot}

$\mathrm{W} 1=2 /(2+2+2+1+1+1)=0,222 \quad \mathrm{~W} 4=1 /(2+2+2+1+1+1)=0,111$

$\mathrm{W} 2=2 /(2+2+2+1+1+1)=0,222 \quad \mathrm{~W} 5=1 /(2+2+2+1+1+1)=0,111$ $\mathrm{W} 3=2 /(2+2+2+1+1+1)=0,222 \quad \mathrm{~W} 6=1 /(2+2+2+1+1+1)=0,111$

2. Langkah kedua, menghitung matriks normalisasi seperti pada Tabel IV

$\mathrm{M}_{11}=2^{0,222}=1,147 \mathrm{M}_{13}=1^{0,222}=1 \mathrm{M}_{15}=1^{0,111}=1$

$\mathrm{M}_{12}=2^{0,222}=1,203 \mathrm{M}_{14}=1^{0,111}=1 \mathrm{M}_{16}=1^{0,111}=1$

TABEL IV. Matriks Normalisasi Metode Gabungan

\begin{tabular}{|c|c|c|c|c|c|c|}
\hline & C1 & C2 & C3 & C4 & C5 & C6 \\
\hline A1 & 1,167 & 1,167 & 1 & 1 & 1 & 1 \\
\hline A2 & 1,277 & 1,277 & 1,167 & 1,080 & 1,080 & 1,080 \\
\hline A3 & 1,361 & 1,361 & 1,277 & 1,130 & 1,130 & 1,130 \\
\hline A4 & 1,430 & 1,430 & 1,361 & 1,130 & 1,167 & 1,167 \\
\hline Pasien & 1,667 & 1,167 & 1,167 & 1 & 1 & 1 \\
\hline
\end{tabular}

3. Langkah ketiga, membuat matriks ternormalisasi terbobot seperti pada Tabel V
$\mathrm{V}_{11}=2 * 1,167=4,812 \quad \mathrm{~V}_{12}=2 * 1,167=4,812$
$\mathrm{V}_{13}=2 * 1=2 \quad \mathrm{~V}_{14}=1 * 1=1$
$\mathrm{V}_{15}=1 * 1=1 \quad \mathrm{~V}_{16}=1 * 1=1$ 
TABEL V. Matriks Ternormalisasi Terbobot

\begin{tabular}{|c|c|c|c|c|c|c|}
\hline & C1 & C2 & C3 & C4 & C5 & C6 \\
\hline A1 & 2,333 & 2,333 & 2 & 1 & 1 & 1 \\
\hline A2 & 2,553 & 2,553 & 2,333 & 1,080 & 1,080 & 1,080 \\
\hline A3 & 2,722 & 2,722 & 2,553 & 1,130 & 1,130 & 1,130 \\
\hline A4 & 2,860 & 2,860 & 2,722 & 1,130 & 1,167 & 1,167 \\
\hline Pasien & 2,333 & 2,333 & 2,333 & 1 & 1 & 1 \\
\hline Max & 2,860 & 2,860 & 2,722 & 1,130 & 1,167 & 1,167 \\
\hline Min & 2,333 & 2,333 & 2 & 1 & 1 & 1 \\
\hline
\end{tabular}

4. Langkah keempat, membuat matriks solusi ideal positif dan solusi ideal negatif pada Tabel VI dan Tabel VII $\mathrm{Al}^{+}=(2,333-2,860)^{2}=0,278$

$\mathrm{A}^{+}=(2,553-2,860)^{2}=0,094$

Pasien $^{+}=(2,333-2,860)^{2}=0,278$

$\mathrm{A} 1^{-}=(2,333-2,333)^{2}=0$

$\mathrm{A}^{-}=\left(2,553-2,333^{2}=0,048\right.$

Pasien $^{-}=(2,333-2,333)^{2}=0$

TABEL VI. Nilai Solusi Ideal Positif Metode Gabungan

\begin{tabular}{|c|c|c|c|c|c|c|}
\hline & C1 & C2 & C3 & C4 & C5 & C6 \\
\hline A1 & 0.278 & 0.278 & 0.521 & 0.017 & 0.028 & 0.028 \\
\hline A2 & 0.094 & 0.094 & 0.151 & 0.002 & 0.007 & 0.007 \\
\hline A3 & 0.019 & 0.019 & 0.028 & 0 & 0.001 & 0.001 \\
\hline A4 & 0 & 0 & 0 & 0 & 0 & 0 \\
\hline Pasien & 0,278 & 0,278 & 0,151 & 0,017 & 0,028 & 0,028 \\
\hline
\end{tabular}

TABEL VII. Nilai Solusi Ideal Negatif Metode Gabungan

\begin{tabular}{|c|c|c|c|c|c|c|}
\hline & $\mathrm{C} 1$ & $\mathrm{C} 2$ & $\mathrm{C} 3$ & $\mathrm{C} 4$ & $\mathrm{C} 5$ & $\mathrm{C} 6$ \\
\hline $\mathrm{A} 1$ & 0 & 0 & 0 & 0 & 0 & 0 \\
\hline $\mathrm{A} 2$ & 0.048 & 0.048 & 0.111 & 0.006 & 0.006 & 0.006 \\
\hline $\mathrm{A} 3$ & 0.019 & 0.019 & 0.028 & 0 & 0.001 & 0.001 \\
\hline $\mathrm{A} 4$ & 0.278 & 0.278 & 0.521 & 0.017 & 0.028 & 0.028 \\
\hline Pasien & 0 & 0 & 0.111 & 0 & 0 & 0 \\
\hline
\end{tabular}

5. Langkah kelima, menghitunga jarak setiap alternatif dengan matriks solusi ideal seperti pada Tabel VIII

$\mathrm{A} 1^{+}=\sqrt{0,278+0,278+0,521+0,017+0,028+0,028}=1,072$

$\mathrm{A} 1^{-}=\sqrt{0+0+0+0+0+0}=0$

TABEL VIII. Jarak Alternatif

\begin{tabular}{|c|c|c|}
\hline & $\mathrm{A}+$ & $\mathrm{A}-$ \\
\hline $\mathrm{A} 1$ & 1,072 & 0 \\
\hline $\mathrm{A} 2$ & 0,597 & 0,476 \\
\hline $\mathrm{A} 3$ & 0,263 & 0,811 \\
\hline $\mathrm{A} 4$ & 0 & 1,072 \\
\hline Pasien & 0,882 & 0,333 \\
\hline
\end{tabular}

6. Langkah keenam, mengkalkulasikan nilai preferensi setiap alternatif terdekat dengan solusi ideal

$\mathrm{V} 1(\mathrm{~A} 1)=0 /(0+1,072)=0$

$\mathrm{V} 2(\mathrm{~A} 2)=0,476 /(0,476+0,597)=0,444$

$\mathrm{V} 3(\mathrm{~A} 3)=0,811 /(0,811+0,263)=0,755$

$\mathrm{V} 4(\mathrm{~A} 4)=1,072(1,072+0,882)=1$

Pasien $=0,333 /(0,333+0,882)=0,274$

7. Langkah ketujuh, menghitung selisih antara Pasien dengan alternatif dan memilih alternatif dengan selisih terkecil seperti pada Tabel IX

$$
\begin{aligned}
& \mathrm{D} 1=|0,274-0|=0,274 \quad \mathrm{D} 2=|0,274-0,444|=0,170 \\
& \text { D3 }=|0,274-0,755|=0,481 \quad \text { D4 }=|0,274-1|=0,726
\end{aligned}
$$

TABEL IX. Selisih dan Alternatif Terpilih

\begin{tabular}{|c|c|c|}
\hline Peringkat & Alternatif & Hasil \\
\hline 1 & Serangan Asma Sedang & 0,170 \\
\hline 2 & Serangan Asma Ringan & 0,274 \\
\hline 3 & Serangan Asma Berat & 0,481 \\
\hline 4 & Serangan Asma Ancaman Jiwa & 0,726 \\
\hline
\end{tabular}

\section{Pengujian dengan Pakar}

Pada tahap pengujian ini dilakukan untuk mengetahui tingkat kesesuaian dari keluaran sistem untuk masingmasing metode WP, TOPSIS dan Gabungan dengan hasil diagnosa dari Pakar dan dibandingkan dengan satu sama lain. Langkah yang dilakukan dalam penelitian ini untuk mendapatkan tingkat kesesuaian atau akurasi yaitu sebagai berikut, pertama penulis memberikan kueisioner yang terdapat kolom-kolom gejala yang mungkin dialami seorang pasien, kedua pakar mengisi kueisoner tersebut gejala yang mungkin dialami pasien berdasarkan pengalaman pakar, ketiga pakar memberikan hasil diagnosa dari gejala tersebut, keempat penulis mengisikan gejala yang terdapat di kuesioner, kelima penulis melakukan diagnosa sistem dan mendapatkan hasilnya, keenam membandingkan hasil diagnosa pakar tersebut dengan diagnosa sistem.

Berikut merupakan perbandingan hasil diagnosa pakar dengan sistem yang seperti pada Gambar 9 dan Gambar 10. Untuk dapat melihat data uji kasus dari pakar dapat di akses pada link berikut ini untuk dr Risky Sp.P https://drive.google.com/open?id=1SH8na5rmd3oQLZpta 96QAJAJruXceQiV dan dr Salim Sp. P https://drive.google.com/open?id=1Q nVJ tgxf5kh2jJCe $\underline{\text { mL0sxBESroGN5u }}$

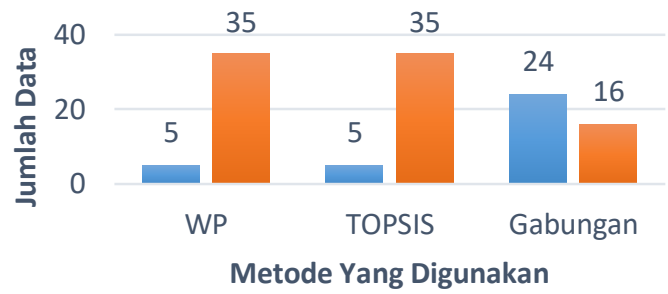

Valid Tidak Valid

Gambar 9. Grafik data kasus pengujian dr.Salim Sp.P

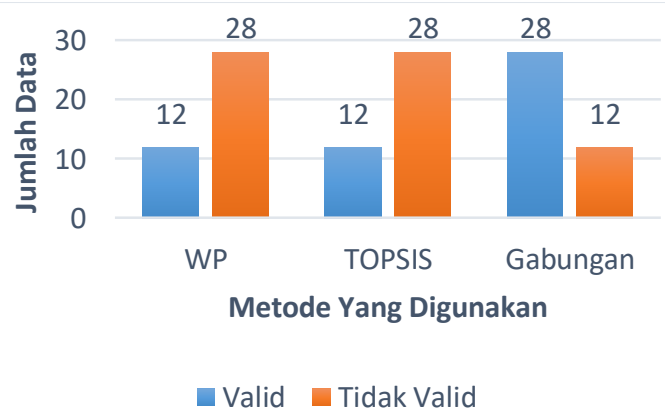

Gambar 10. Grafik data kasus pengujian dr.Risky Sp.P 
Setelah dilakukannya pengujian untuk mengetahui tingkat kesesuaian atau akurasi dari masing-masing metode baik WP, TOPSIS maupun Gabungan didapatkan hasil yang berbeda. Untuk pakar pertama dr. Salim Sp.p, pengujian metode WP memiliki tingkat kesesuaian yaitu $12,5 \%$, metode TOPSIS memiliki tingkat kesesuaian yaitu $12,5 \%$ serta metode Gabungan memiliki tingkat kesesuaian yaitu $60 \%$. Untuk pakar kedua dr. Risky Sp.p, pengujian metode WP memiliki tingkat kesesuaian yaitu 30\%, metode TOPSIS memiliki tingkat kesesuaian yaitu 30\% serta metode Gabungan memiliki tingkat kesesuaian yaitu 70\%.

Apabila dibandingkan dengan penelitian sebelumnya yang membahas mengenai perbandingan metode WP dan TOPSIS, didapatkan hasil bahwa metode WP dan TOPSIS memberikan keluaran yang sama untuk alternatif tiga desa[12]. Pada penelitian ini, dimana untuk metode WP dan TOPSIS baik di pakar pertama maupun kedua memiliki tingkat kesesuaian yang sama. Hal ini disebabkan karena metode WP dan TOPSIS memberikan alternatif keluaran penyakit yang sama satu sama lain. Sedangkan untuk metode Gabungan memberikan alternatif yang berbeda sehingga mempengaruhi tingkat kesesuaian dari metode Gabungan.

Dibandingkan dengan penelitian lainnya yang juga membahas perbandingan antara metode WP dan TOPSIS yaitu menunjukkan bahwa metode TOPSIS lebih unggul dibandingkan dengan metode WP[13]. Penelitian tersebut menunjukkan bahwa pada uji coba terhadap 30 data didapatkan metode TOPSIS persentase error ratenya itu $27 \%$ sedangkan metode WP 33\%. Hal inilah yang menjadikan acuan penulis untuk melakukan penggabungan kedua metode ini disebabkan karena kedua metode memiliki kekurangan dan kelebihan yang dapat saling menutupi sehingga menjadikan sebuah metode yang lebih baik lagi dalam penggunaannya di sistem pakar.

Tingkat kesesuaian yang dihasilkan dari pengujian masing-masing metode menunjukkan bahwa metode Gabungan lebih unggul dibandingkan dengan metode WP dan metode TOPSIS. Hal tersebut disebabkan karena metode Gabungan memiliki perhitungan sistem yang lebih baik dikarenakan tidak memperhatikan cost atau biaya serta memilih selisih terkecil antara variabel pasien dengan serangan asma yang diderita sehingga memberikan hasil diagnosa yang sama dengan hasil diagnosa yang diberikan oleh pakar.

Namun, metode Gabungan memiliki tingkat kesesuaian yang tidak terlalu tinggi yaitu antara $60 \%$ sampai $70 \%$. Dalam penelitian ini, hal tersebut disebabkan karena dalam membangun sebuah sistem pakar diperlukan akuisisi pengetahuan yang tepat sehingga memberikan hasil diagnosa yang lebih baik, penentuan kriteria dan subkriteria serta penentuan bobot dan sifat tiap kriteria harus benarbenar tepat karena berpengaruh terhadap hasil akhir dan juga dalam penelitian ini hanya menggunakan 40 contoh kasus yang diberikan oleh masing-masing pakar[12]. Dengan melakukan beberapa perbaikan seperti memperbanyak data tes dan dapat mendiagnosa penyakit secara umum dengan kelompok gejala yang sama, metode ini cukup baik untuk dapat digunakan dalam mendiagnosa suatu penyakit.

\section{KESIMPULAN DAN SARAN}

\section{A. Kesimpulan}

Berdasarkan hasil analisa dan pengujian terhadap penggabungan metode Weighted Product dan TOPSIS dalam mendiagnosa serangan asma, disimpulkan bahwa:

1. Perbandingan penelitian ini dengan penelitian sebelumnya antara lain melakukan penggabungan metode yang tidak sering digunakan dalam sistem pakar yaitu WP dan TOPSIS, penelitian ini melibatkan hasil diagnosa dengan pakar sehingga didapatkan tingkat akurasi untuk tiap metode serta menggunakan data yang lebih banyak dengan alternatif 4 level serangan asma.

2. Berdasarkan pengujian yang telah dilakukan tingkat kesesuaian yang diberikan oleh metode WP dan TOPSIS 40 kasus dari pakar pertama yaitu $12,5 \%$ dan pakar kedua yaitu 30\%. Didapatkan rata-rata $21,25 \%$.

3. Metode Gabungan dari metode WP dan TOPSIS cukup efektif dikarenakan tingkat kesesuaian yang diberikan oleh metode Gabungan dengan 40 kasus untuk masing-masing pakar yaitu $60 \%$ dan $70 \%$ sehingga rata-rata yang didapatkan dari dua pengujian tersebut yaitu $65 \%$ dan terdapat kenaikan tingkat kesesuaian sekitar $43,75 \%$.

\section{B. Saran}

Hal-hal yang menjadi saran untuk pengembangan sistem ini agar menjadi lebih baik adalah sebagai berikut:

1. Diharapkan dapat dibangun sebuah sistem pakar diagnosa serangan asma yang lebih lengkap dan lebih baik lagi dengan menggunakan metode gabungan WP dan TOPSIS.

2. Untuk meningkatkan akurasi diperlukan beberapa hal antara lain sub gejala dari gejala-gejala yang ada dengan jumlah yang sama agar pada basis pengetahuan didapatkan nilai yang lebih beragam dan menggunakan data tes yang lebih banyak serta meningkatkan jumlah pakar yang terlibat dalam membangun sistem.

\section{DAFTAR PUSTAKA}

[1] S. Iswanti dan S. Hartati, Sistem Pakar dan Pengembangannya, Pertama. Yogyakarta: Graha Ilmu, 2008.

[2] Pedoman Pengendalian Asma. Jakarta: Departemen Kesehatan Republik Indonesia, 2009.

[3] Joan Angelina Widians Ikrimah Hidayati, "Sistem Pendiagnosa Penyakit Asma pada Anak dengan Metode Certainty Factor," Semin. Nas. Teknol. Inf. dan Multimed., p. 6, 2016.

[4] A. Muhyiddin dan E. Mulyanto, "Sistem Pakar Diagnosa Level Penyakit Asma Menggunakan Metode Fuzzy Tsukamoto," p. 9, 2015. 
[5] Rachmawati, D. J. Damiri, dan A. Susanto, "Aplikasi Sistem Pakar Diagnosis Penyakit Asma," J. Algoritm. STT Garut, p. 7, 2012.

[6] K. Hanum dan Subiyanto, "Sistem Diagnosa Level Asma Menggunakan Fuzzy Inference System," J. Ners, vol. 10, p. 7, 2015.

[7] D. T. Wahyuningtyas, "Sistem Pendukung Keputusan Diagnosa Penyakit Paru-Paru dengan Metode Weighted Product guna Membantu Proses Anamnesa Berbasis Mobile," J. Inf. Technol., vol. 05, p. 7, 2017.

[8] P. Sihaloho dan W. Ginting, "Diagnosa Penyakit Hepatitis Menggunakan Metode Weighted Product," MEANS (Media Inf. Anal. dan Sist., vol. 02, p. 5, 2017.

[9] Y. W. N. Fitriya, N. Hidayat, dan Marji, "Implementasi Metode Weighted Product - Certainty Factor untuk Diagnosa Penyakit Malaria," J. Pengemb. Teknol. Inf. dan Ilmu Komput., vol. 02, no. 05, pp. 2158-2163, 2017.

[10] A. S. H, A. Pujiastuti, dan L. P. Susanti, "Sistem Pakar Untuk Mendiagnosa Penyakit Dan Hama Pada Tanaman Salak Di Turi Sleman,” vol. 6, 2017.

[11] F. Setiawan, I. Lestari, dan D. Hidayatul, "Sistem Pendukung Keputusan Diagnosa Penyakit Pada Anak Dengan Metode Simple Additive Weighting (SAW) Dan Technique Order Preference By Similarity To Ideal
Solution(TOPSIS)," J. Aksara Komput. Terap., vol. 06, no. 02, 2017.

[12] Ni Kadek Sukerti, "Analisis Perbandingan Penerima Bantuan Kemiskinan dengan Metode Weighted Product (WP) dan TOPSIS," J. Ilm. DASI, vol. 17, p. 7, 2016.

[13] S. A. Fitriani, "Perbandingan Metode Weighted Product dengan Metode Technique For Order Preference By Similarity To Ideal Solution dalam Pendukung Keputusan Perekrutan Siswa/Mahasiswa Praktek Kerja Lapangan (PKL) (Studi Kasus: PT. Industri Telekomunikasi Indonesia)," Universitas Pendidikan Indonesia, 2014.

[14] Putra Jaya, "Sistem Pendukung Keputusan Penentuan Bonus Karyawan Menggunakan Metode Weighted Product (WP) (Studi Kasus: PT.Gunung Sari Medan)," Pelita Inform. Budi Darma, vol. 5, p. 6, 2013.

[15] Muhammad Gugi Guntara, "Aplikasi Metode ANP (Analytic Network Process) Dan TOPSIS (Technique For Order Preference By Similarity To Ideal Solution) Untuk Pengambilan Keputusan Alternatif Pemasaran Terbaik Pada Hotel Citi Inn Medan," Universitas Sumatera Utara, 2013. 